\title{
Snow cover dynamics and geohazards: a case study of Bhilangna watershed, Uttarakhand Himalaya, India
}

\author{
Manish Kumar ${ }^{1 *}$ and Pankaj Kumar²
}

\begin{abstract}
This study examines snow covered area (SCA) and associated geohazards in the Bhilangna watershed using the Normalized Difference Snow Index. Two Landsat images from 1990 and 2010 were analyzed. In order to estimate the average elevation of the snowline, a digital elevation model from the Shuttle Radar Topography Mission was used. In 1990, $124 \mathrm{~km}^{2}$ (9\% of the watershed) was snow covered. In 2010, $96 \mathrm{~km}^{2}$ (7\%) was snow covered. Therefore, during the study period (i.e., 1990-2010) SCA decreased by $28 \mathrm{~km}^{2}$ (2\%). Four snow types were identified and mapped: frost, fine, medium and coarse snow. In 1990, $38 \mathrm{~km}^{2}$ (30 \% of SCA) was covered by frost snow, $86 \mathrm{~km}^{2}(69 \%)$ was covered by fine snow, $<1 \mathrm{~km}^{2}(<1 \%)$ was covered by medium granular snow, and an insignificant area was covered by coarse snow. In 2010, frost and fine snow covered $19 \mathrm{~km}^{2}(20 \%)$ and $76 \mathrm{~km}^{2}$ (79\%) respectively, medium snow covered $1 \mathrm{~km}^{2}(1 \%)$, and coarse snow was not traced. The snowline shifted from $4611 \mathrm{~m}$ in 1990 to $4698 \mathrm{~m}$ in 2010. These observations show the variability of snow cover in the Bhilangna watershed.
\end{abstract}

Keywords: Shuttle Radar Topography Mission, Normalized Difference Snow Index, Snow line, Geohazard

\section{Introduction}

Snow cover plays an important role in the climate system by changing the energy and mass transfer between the atmosphere and the surface (Khosla et al., 2011). The snow is most important land cover type in the Himalaya, which act as an important source of fresh water for rivers (Kulkarni, 2007). The monitoring of its spatial extent is an important aspect of research because it provides insight as to the amount of water to be expected from snowmelt available for runoff and water supply (Salomonsona and Appel 2004). The reliable information on spatial extent of snow cover and its dynamics may be useful in several research and developmental activities. This information may prove as a better input in hydropower generation system, water management, strategic planning and many other developmental activities in any region. In addition, the snow cover itself is a surface condition that affects the Earth's radiation

\footnotetext{
* Correspondence: manish.ks1@gmail.com

${ }^{1}$ Department of Geography, Kalindi College, University of Delhi, Delhi 110008, India

Full list of author information is available at the end of the article
}

balance (Cohen, 1994; Cohen and Entekhabi, 2001; Douville and Royer, 1996; Foster et al., 1996; Stieglitz et al. 2001; Yang et al., 1999). Hence, the reliable and updated information on snow cover may also be used in hydrological cycle and climate modeling. Obtaining snow cover information on repetitive basis from vast snow covered areas of Himalaya using conventional survey and mapping (manned snow-meteorological observatories) techniques are very difficult due to high altitude, inaccessible and rugged mountain terrain. In the recent years, Remote Sensing technique has emerged as a popular viable substitute for real-time, year-round and large spatial coverage for monitoring and process studies over vast, rugged and remote areas (Konig et al., 2001, Hall et al. 2005). This technique has been used extensively for snow-cover monitoring in the Himalayan region with the help of numerous satellite sensors (Kulkarni and Rathore, 2003). Geographical Information System (GIS) along with remote sensing technology facilitate fast and efficient ways to analyze, visualize and report the seasonal snow-cover changes (Kaur et al. 2009). In the mid1960s, snow was successfully mapped from space on a weekly basis following the launch of the Environmental

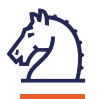

Springer 
Science Service Administration (ESSA-3) satellite which carried the Advanced Vidicon Camera System (AVCS) that operated in the spectral range of $0.5-0.75 \mu \mathrm{m}$ with a spatial resolution at nadir of $3.7 \mathrm{~km}$. The National Oceanographic and Atmospheric Administration (NOAA) has measured snow cover on weekly basis in the Northern Hemisphere since 1966 using a variety of sensors, including the Scanning Radiometer (SR), Very High Resolution Radiometer (VHRR) and the Advanced Very High Resolution Radiometer (AVHRR) (Matson et al., 1986; Matson, 1991). The current NOAA product is a daily snow-cover product (Ramsay, 1998). This system provide daily, global observations to monitor the variability in space and time in the extent of snow cover utilizing space borne sensors (Frei and Robinson, 1998; Rango et al. 2000; Robinson et al. 1993). The different medium resolution satellite sensors, e.g., Landsat MSS and TM have been used for the mapping of snow cover area over drainage basins (Dozier et al 1981; Rango and Martinec 1982; Dozier 1984, 1989).

Initially, the mapping process on satellite data was largely based on the conventional techniques such as manual delineation of snow cover boundaries, segmentation of ratio images and hard or crisp classification (Negi et al., 2009). Other analysis techniques such as visual, hybrid (visual and supervised classification) have also been used to estimate the areal extent of snow cover (Kulkarni and Rathore, 2003). The major difficulties in monitoring snow cover using remote sensing techniques in Himalayan region are the mountain shadow and confusing signature of snow and cloud in the visible and near-infrared region. Some researchers have introduced the reflectance ratio/index approaches to remove the effects of radiometric errors due to changing effects in the atmosphere and topographical changes across the scene (Slater, 1980). To address this issue, normalized difference snow index (NDSI), along with the threshold tests have been used successfully for snow cover mapping using satellite data (Hall et al., 1995, 2002, Kulkarni and Rathore 2003, 2006; Gupta et al., 2005; Negi et al., 2008). The NDSI is a spectral band ratio like normalized difference vegetation index -NDVI (Tucker 1979, 1986; Townshend and Tucker 1984) that takes advantage of the spectral differences of snow in short-wave infrared (SWIR) and visible spectral bands (green) to identify snow versus other features in a scene (Nolin and Liang, 2000). This is an effective index for mapping snow cover in rugged terrain (Hall et al., 1995). It can delineate and map the snow under mountain shadow and is not influenced by topographic conditions (Kulkarni et al., 2006). Shafer and Leaf (1979) concluded that the Landsat satellite imagery has sufficient quality to monitor the snow cover area accurately.

In the light of above facts, the present study is an attempt to monitor and map out the snow-cover and snowline variation in Bhilangna watershed analyzing Landsat TM data set of years 1990 and 2010 using remote sensing and GIS techniques.

\section{Study area}

The study was carried out in the Bhilangna watershed, located in the Tehri Garhwal district of Uttarakhand, India which extends between $30^{\circ} 19^{\prime} 46^{\prime \prime} \mathrm{N}$ to $30^{\circ} 51^{\prime}$ $36^{\prime \prime} \mathrm{N}$ latitudes and $78^{\circ} 28^{\prime} 27^{\prime \prime} \mathrm{E}$ to $79^{\circ} 01^{\prime} 50^{\prime \prime} \mathrm{E}$ longitudes, encompasses an area of $1420.64 \mathrm{sq} \mathrm{km}$ in the Garhwal Himalaya, India. The river Bhilangna is a major tributary of the Bhagirathi River. The mainstream Bhilangna, rises at the foot of the Khatling Glacier (elevation $3717 \mathrm{~m}(12,195 \mathrm{ft})$ ) approximately $50 \mathrm{~km}$ (31 mi) south of the ice cave at Gaumukh, traditionally considered the source of both the Bhagirathi and the Ganges and flows into the Bhagirathi at Old Tehri, the site of the Tehri dam. The altitude of the watershed varies between $621 \mathrm{~m}$ and $6427 \mathrm{~m}$. A location map is shown in Fig. 1.

\section{Materials and methods}

The methodology for determining the snow cover pattern and dynamics of Bhilangna watershed is described in the following steps:

1. The base map of study area Bhilangna watershed was prepared in the ArcGIS software by using the survey of India toposheet scaled at 1:50,000 and then watershed boundary was checked and corrected by superimposing the DEM data (Digital elevation model) derived from the SRTM digital elevation dataset with $90 \mathrm{~m}$ spatial resolution and $\pm 15 \mathrm{~m}$ vertical accuracy. A rectification have been done in Landsat 5 TM images using the ArcGIS 9.3 software and the images have been given the base map coordinates (i.e., UTM projection, and $44 \mathrm{~N}$ zone) for the purpose to identify the study area in the image.

2. To work out with snow cover area, remotely sensed data are extremely valuable. To study the spatial and temporal pattern of snow cover and snow lines in the watershed, a set of two Landsat 5, Thematic Mapper TM images were procured in digital format for the years October 15, 1990 and October 11, 2010. Landsat 5, Thematic Mapper TM with spatial resolution of 30 meter was stacked on ERDAS imagine software. The Landsat data set provided by Global Land Cover Facility site were radiometrically and geometrically (ortho-rectified with UTM/WGS 84 projection) corrected.

3. To segregate the snow covered from non-snow covered area NDSI was estimated using Band 2 


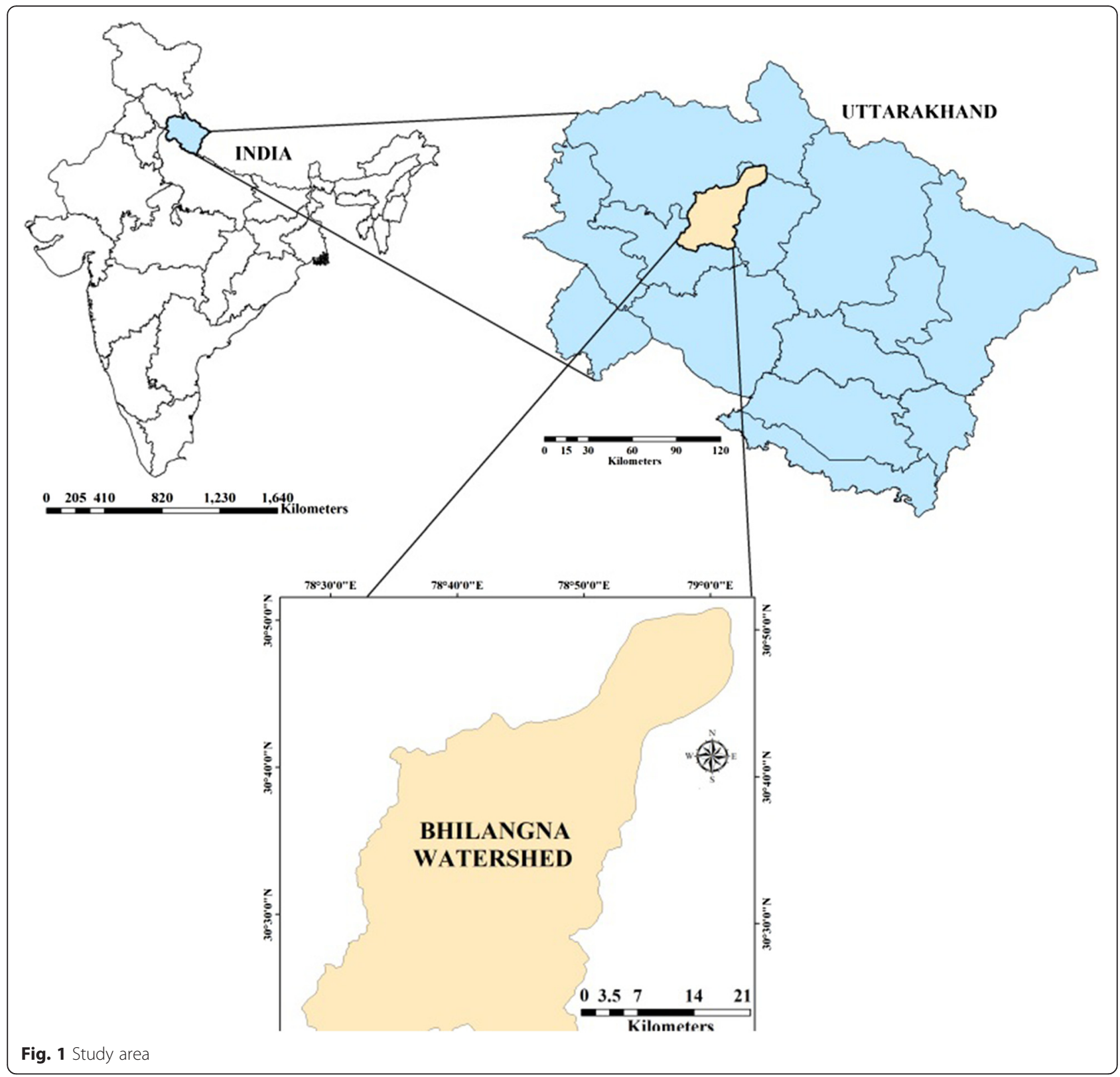

and Band 5 for the both TM images of 1990 and 2010 by the following equation (Hall et al.2002):

NDSI $=\frac{\text { TM Band } 2-\text { TM Band } 5}{\text { TMBand } 2+\text { TM Band } 5}$

Where, TM Band 2 and TM Band 5 are the reflectance of the green and shortwave infrared bands, respectively.

The study area, i.e., Bhilangna watershed was clipped using its shape file from NDSI image. The NDSI clipped raster data of the years 1990 and 2010 were then reclassified into two classes i.e. snow cover and non-snow cover area in ArcGIS software, by using the Spatial Analyst tool. To segregate the snow covered from non-snow covered area, Hall et al. (1998) suggested a NDSI threshold of $>0.40$ which has been used to map snow cover. After displaying the NDSI imagery on the screen of Arc map, the lower limit of snow cover in the watershed area was digitized for both years. By superimposing the lower limit of snow cover for both the years, the area of change from snow cover area to non-snow cover area was worked out.

4. The NDSI image of the study area has been further classified into four snow cover sub categories based on the threshold value suggested by Hall et al. (1998, 1995) namely coarse granular snow (i.e., $>0.937 \mathrm{~nm}$ ), medium granular snow (i.e., $0.848 \mathrm{~nm}$ to $0.937 \mathrm{~nm}$ ), 


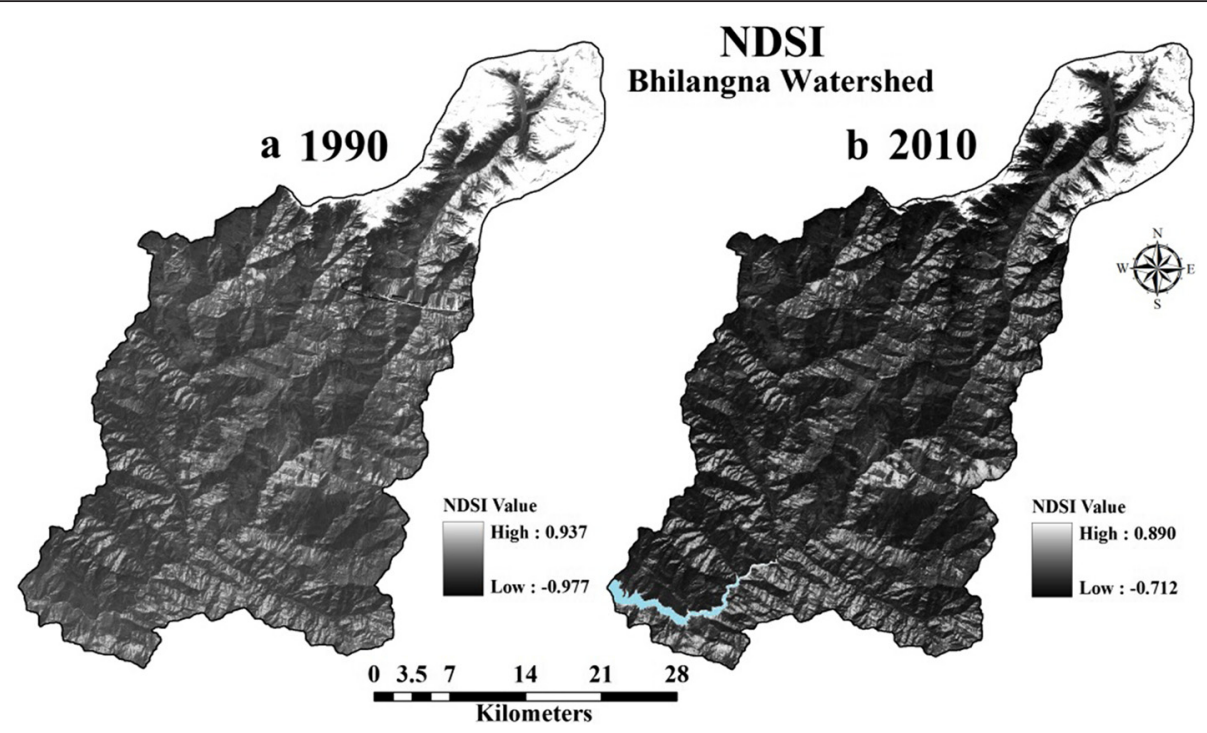

Fig. 2 NDSI of 1990 and 2010

fine granular snow (i.e., $0.611 \mathrm{~nm}$ to $0.848 \mathrm{~nm}$ ) and frost (i.e., $0.414 \mathrm{~nm}$ to $0.611 \mathrm{~nm}$ ). This step was performed in ArcGIS software, in which the NDSI images were reclassified in 'Spatial Analyst toolbar' entering threshold values.

5. The NDSI was reclassified into four categories i.e., coarse granular snow, medium granular snow, fine granular snow and frost were then converted into vector based polygon format for the estimation of total snow cover area and to know about the area falling within each category of snow cover.

6. In order to draw snow line, a shape file was created in ArcGIS software in 'Arc catalogue' and snow line has been digitized for the year 1990 and 2010.

7. To estimate snow line height, the snow line of both the years were overlaid on the DEM data and then a point shape file has been created in Arc-catalogue and keeping the snapping mode on, the digitization was done, over the snowline of one year i.e., 1990 and then the digitized points were masked by the mask function from DEM data, so, that each point bear some heights and then those points were exported into the Microsoft excel sheet and the average height have been estimated. The same process was repeated for the year 2010 snow line height estimation.

\section{Results and discussion}

Spatio-temporal dynamics of snow cover

To study the spatio-temporal pattern of snow cover in Bhilangna watershed, a set of two TM images were analyzed using NDSI model in ERDAS Imagine software.

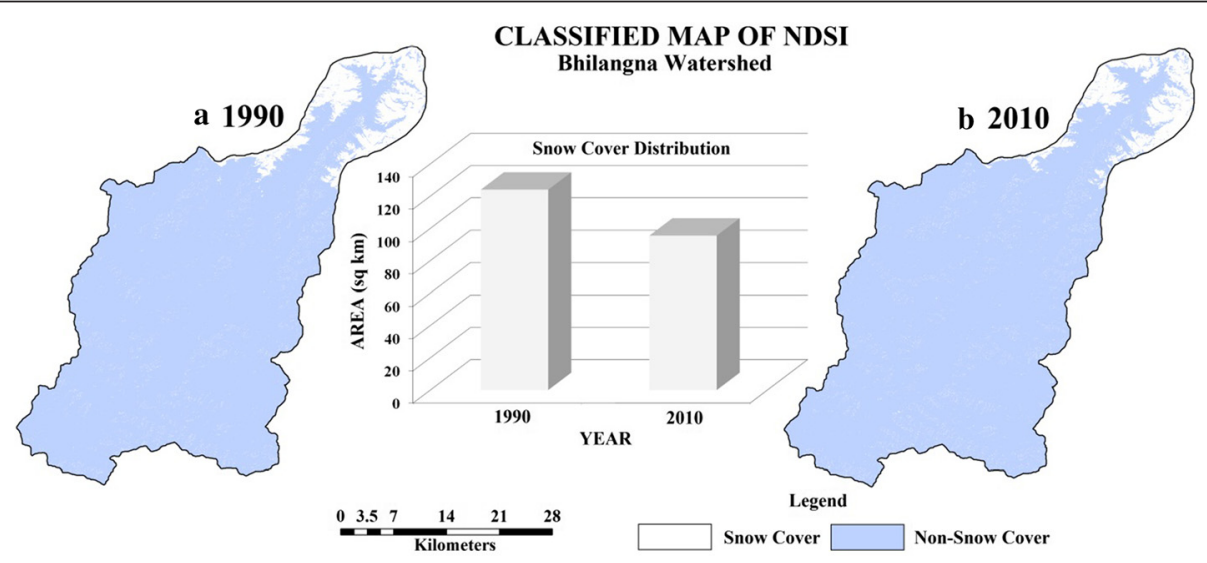

Fig. 3 Snow cover classification and distribution of NDSI 
Table 1 Snow cover in Bhilangna Watershed

\begin{tabular}{lcc}
\hline Year & \multicolumn{2}{l}{ Snow cover status } \\
\cline { 2 - 3 } & Sq km & $(\%)$ \\
\hline 1990 & 124.03 & 8.73 \\
2010 & 95.52 & 6.72 \\
Change (1990-2010) & 28.51 & 2.01 \\
\hline
\end{tabular}

Source: Landsat TM

Initially, the DNs of the seven-band of TM images were processed and converted into extra-atmospheric reflectance values (reflectance above the atmosphere), using the published Landsat TM post-launch gains and offsets (ENVI software version 3.2). The resultant reflectance images were then used for NDSI estimation. NDSI was calculated on a pixel-by-pixel basis and generated gray scale images with high values (bright pixels) representing snow. The results obtained through this analysis are diagrammatically illustrated in Fig. 2 which depicts the distribution of NDSI variation in year 1990 and 2010 in the study area. A pixel value in the resultant NDSI images varies between 0.937 to -0.977 and 0.890 to -0.712 in the year 1990 and 2010 respectively. On the basis of threshold value of $>0.40$, both NDSI images were classified to map out the snow cover (i.e., if NDSI > 0.40 pixel is snow, else not snow). Figure 3 depicts spatial distribution of snow cover area in 1990 and 2010 in the study area. The calculation of area under snow cover during the years 1990 and 2010 were worked out which is represented in Table 1 . The obtained result from NDSI reveals that in the year 1990 about $124.03 \mathrm{sq} \mathrm{km}(8.73 \%)$ area of the Bhilangna
Watershed was under snow cover while in 2011 the snow cover was found $95.52 \mathrm{sq} \mathrm{km}(6.72 \%)$. It is also shown in Table 1 that the snow cover area in the Bhilangna watershed got depleted considerably during the 20 years of research span (i.e., 1990 to 2010). During this period, about $28.51 \mathrm{sq} \mathrm{km}$ snow cover of the Bhilangna watershed has been converted into non-snow cover area at an average rate of $1.42 \mathrm{sq} \mathrm{km} /$ year.

In order to identify the sub classes of snow cover, NDSI images of the year 1990 and 2010 were analyzed using Spatial Analyst toolbar in ArcGIS software. This analysis was performed on the basis of threshold values suggested by Hall et al. $(1998,1995)$. Four snow sub classes were mapped on the NDSI images, viz., a. Coarse granular snow; b. Medium granular snow; c. Fine granular snow; d. Frost. Figure 4 and Table 2 reveals that in the year 1990, about $37.82 \mathrm{sq} \mathrm{km}(30.49 \%)$ area was covered by frost snow, $85.74 \mathrm{sq} \mathrm{km}(69.12 \%)$ area under fine granular snow, $0.47 \mathrm{sq} \mathrm{km}(0.37 \%)$ area under medium granular snow and $0.0018 \mathrm{sq} \mathrm{km}(0.0014 \%)$ area was covered by coarse granular snow while during the year 2010 the area under frost and fine granular cover classes were found to be $18.73 \mathrm{sq} \mathrm{km}(19.60 \%)$ and $75.68 \mathrm{sq} \mathrm{km}(79.22 \%)$ respectively while the medium granular snow cover was found to be $1.11 \mathrm{sq}$ $\mathrm{km}(1.16 \%)$. The result reveals that due to overall decrease in the snow cover area, the frost and fine granular snow was also decreasing.

\section{Spatio-temporal pattern and dynamics of snowline}

In order to analyze snowline and their shifting, the digitization process was performed using Arc catalogue and ArcMap editor in ArcGIS software. The snowlines were digitized for the year 1990 and 2010 (Fig. 5). In order to estimate snow line height, DEM

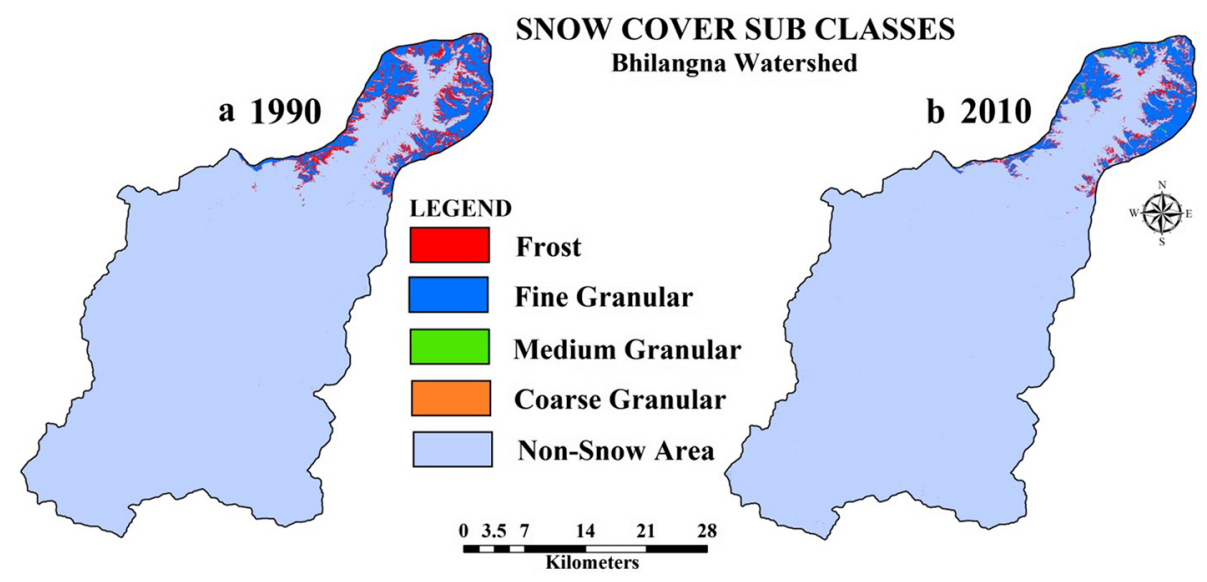

Fig. 4 Snow cover sub classes 
Table 2 Snow cover sub classes and change detection (1990-2010)

\begin{tabular}{|c|c|c|c|c|c|c|}
\hline \multirow{3}{*}{$\begin{array}{l}\text { Snow cover } \\
\text { classes }\end{array}$} & \multirow{3}{*}{$\begin{array}{l}\text { NDSI } \\
\text { threshold } \\
\text { value } \\
\text { (Hall et al. } \\
\text { 1995, } \\
\text { 1998) }\end{array}$} & \multicolumn{2}{|l|}{1990} & \multicolumn{2}{|l|}{2010} & \multirow{3}{*}{$\begin{array}{l}\text { Change (1990-2010) } \\
\text { Snow area } \\
\mathrm{km}^{2}\end{array}$} \\
\hline & & \multicolumn{2}{|c|}{ Snow area } & \multicolumn{2}{|c|}{ Snow area } & \\
\hline & & $\mathrm{km}^{2}$ & $(\%)$ & $\mathrm{km}^{2}$ & (\%) & \\
\hline Frost & 0.414 & 37.82 & 30.49 & 18.73 & 19.60 & -19.09 \\
\hline Fine granular & 0.611 & 85.74 & 69.12 & 75.68 & 79.22 & -10.06 \\
\hline Medium granular & 0.848 & 0.47 & 0.37 & 1.11 & 1.16 & -0.64 \\
\hline Coarse granular & 0.937 & 0.0018 & 0.0014 & \multicolumn{2}{|c|}{ Not Traceable } & - \\
\hline
\end{tabular}

Source: Landsat TM

data was used and analyzed. The results depict that in 1990, the average height of snowline of Bhilangna watershed was 4611 meters above the mean sea level and in year 2000 it was shifted to 4698 meters. This shift in higher elevation is due to decrease in snow cover area. Hence, the total shifting of snowline was observed about 87 meters during research span, at the rate of $4.35 \mathrm{~m} /$ year.

\section{Snow cover and geohazard}

The dynamics of Glacial and periglacial environment are strongly influenced by climate change. Retreat of snowline and degradation of permafrost can lead to horrendous experience never witnessed before. This coupled with human activities intensifies potential conflict with natural geohazards. Few of the major geohazards are landslide, ground subsidence, snow avalanches and fluvial scour. Hazard recognition and analysis are the vital steps that are required for any risk assessment.

Combination of glacial hazards such as hazards from glacial clad volcanoes, glacier related flood, paraglacial mass movement lead to the most severe glacier catastrophe. Long term trends in temperature or other climatic variables can be known by changes in seasonal snowline elevation.

Landslide may occur due to bedrock discontinuities in the headscarp and may be triggered by cracking of steeply dipping slope bounded by discontinuities (Dortch et al., 2008). Snow cover and geohazards in high mountain regions are associated with each other. The area under investigation occupies a complex geological and tectonic set-up. Uttarakhand Himalaya lying in the western part of Himalayan range of Indian sub-continent, snow cover plays an important role in the climate system by changing the energy and mass transfer between the atmosphere and surface. Climate change induced snow melting releases more water trapped in snow and glacier. Water availability on moderate to steep sloppy terrain makes the watershed more vulnerable to various geohazards such as avalanches, landslide, rockfall etc. as it acts as lubricant (Fig. 6).

Frequent avalanches and rockfall in the river valley result in the damming of river channel and formation

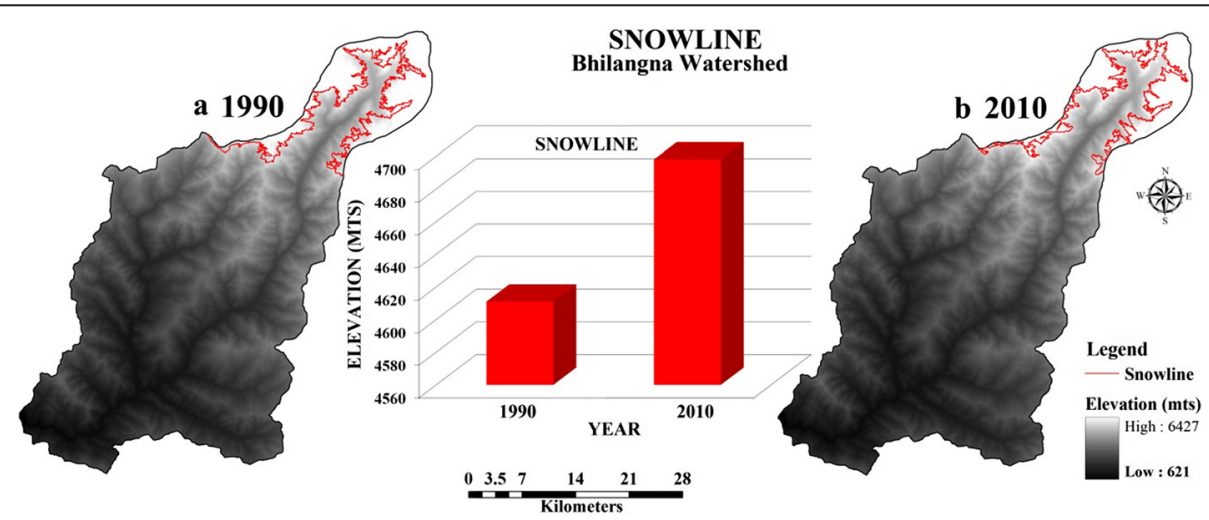

Fig. 5 Snowline and its elevation 


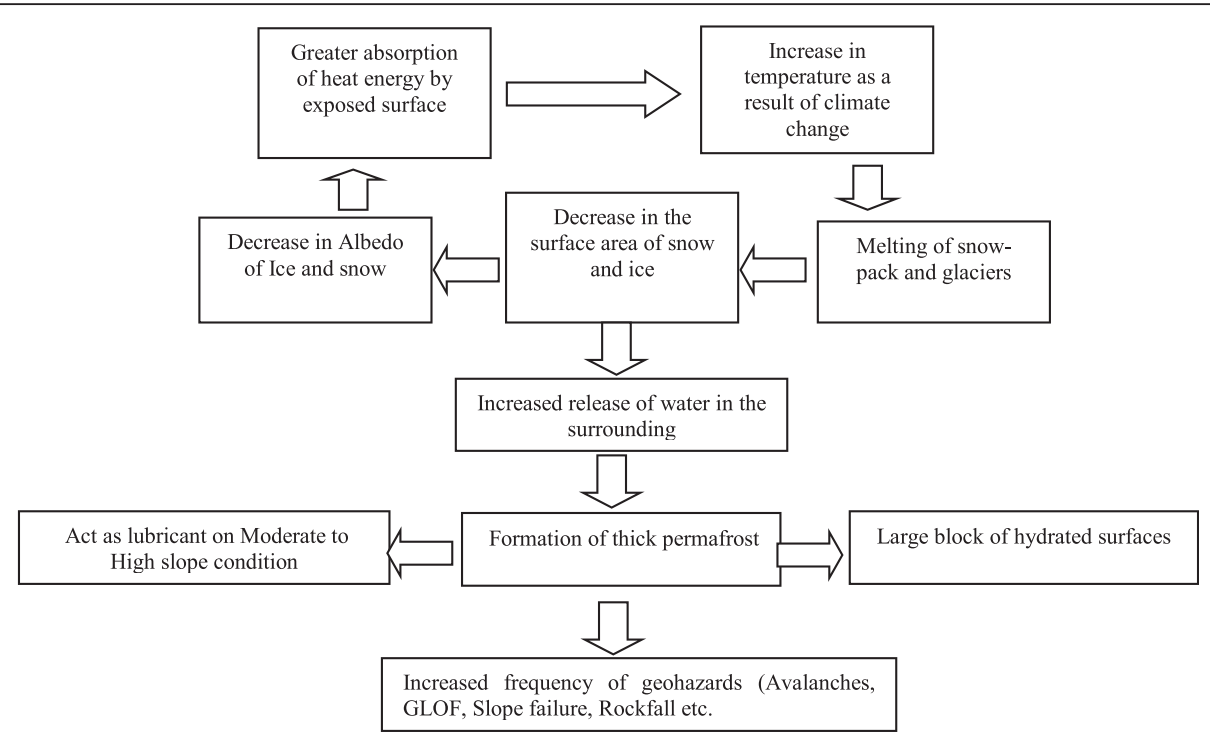

Fig. 6 Snow Cover and Geohazard. Source: modified after Knight, 1999

of Lake behind the big builders of rocks and debris. This results into Landslide Lake Outburst Floods (LLOFs) and many secondary LLOFs in the highly unstable and fragile terrain of Bhilangna Watershed. Increased frequency of these geohazards and snow cover melting in the recent decades are the manifestation of global climate change.

\section{Conclusion}

In this study, Landsat TM images of the year 1990 and 2010 were processed in remote sensing and GIS software to monitor snow cover in Bhilangna watershed of Garhwal Himalaya. This study demonstrate the usefulness of remote sensing and GIS techniques in analyzing spatial extent, nature and magnitude of snow cover area. This study provides beneficial insight into the extent and nature of snow cover changes that has taken place in the watershed from 1990 to 2010, and lays the foundation for further research to be conducted. This study reveals that during the last two decades about $28.51 \mathrm{sq} \mathrm{km}$ area of the watershed has been converted into non-snow cover area. With the help of these data, it can be extrapolated that the snow cover area in Bhilangna watershed is depleting at an average rate of $1.42 \mathrm{~km}^{2} /$ year. It is evident from this study that the snow cover area is depleting steadily in the Garhwal Himalaya. It may be due to environmental degradation and global warming. The continued depletion of snow cover in the study area may result in severe environmental degradation and ecological damages. A periodical monitoring of snow cover through digital processing of satellite images of different dates may play a vital role in environmental planning and watershed management.

\section{Competing interests}

The authors declare that they have no competing interests.

\section{Authors' contribution}

MK has collected the satellite data from various sources, performed the classification and drafted the manuscript. PK has done the statistical analysis. Both the author modified and enriched the final manuscript more relevant and rational. The authors read and approved the final manuscript.

\section{Authors' Information}

The corresponding author, Dr. Manish Kumar is serving as an Assistant Professor at Kalindi College, University of Delhi, is professionally a Geographer. From January 2009 to December 2014, Dr. Kumar served as Course In-Charge of M.Sc. Remote Sensing and GIS Programme of Kumaun University, Uttarakhand. Dr. Kumar has worked as Research Associate on UNDP Project on "'Rurbanization': Making Small Towns Hubs of Rural Productivity at Delhi Policy Group. Dr. Kumar has also served as Visiting Faculty at School of Planning and Architecture, New Delhi. Dr. Kumar holds a PhD from Kumaun University, Nainital, Uttarakhand. He also holds a Post Graduate Diploma in Remote Sensing and GIS from Indian Institute of Remote Sensing, ISRO, Dehradun, Uttarakhand. His area of research domain includes application of remote sensing and GIS in urban and regional planning, urban heat island, land use and land cover dynamics, climate change, snow cover dynamics etc.

Dr. Pankaj Kumar,(MA, Ph.D) is working as Assistant Professor in the Department of Geography, Delhi School of Economics, University of Delhi. Dr. Kumar did his Graduation, Master, M.Phil and Ph.D from Delhi University. His specialization is Mountain Environment, Applied Glaciology, Remote Sensing and Geographical Information System (GIS) and Regional and Urban Geography.

\section{Author details}

${ }^{1}$ Department of Geography, Kalindi College, University of Delhi, Delhi 110008, India. ${ }^{2}$ Department of Geography, Delhi School of Economics, University of Delhi, Delhi 110007, India.

Received: 10 October 2014 Accepted: 31 January 2016

Published online: 23 February 2016 


\section{References}

Cohen, J. 1994. Snow and climate. Weather 49: 150-155.

Cohen, J., and D. Entekhabi. 2001. The influences of snow cover on Northern Hemisphere climate variability. Atmosphere- Ocean 39(1): 35-53.

Dortch, J.M., Owen, L.A., Haneburg, W.C., Caffee, M.W., Dietsch, C., and Kamp, U. 2009. Nature and Timing of Large Landslides in the Himalaya and Transhimalaya in Northen India. Quaternary Science Reviews, 28: 1037-1054.

Douville, H., and J.F. Royer. 1996. Sensitivity of the Asian summer monsoon to an anomalous Eurasian snow cover within the Meteo- France GCM. Climate Dynamics 12(7): 449-466.

Dozier, J.F. 1984. Snow reflectance from Landsat-4 Thematic mapper. IEEE Transactions on Geosciences and Remote Sensing 22(3): 323-328.

Dozier, J. 1989. Spectral signature of alpine snow cover from the Landsat Thematic Mapper. Remote Sensing of Environment 28: 9-22.

Dozier, J., S.R. Schneider, and D.F. Mcginnis Jr. 1981. Effect of grain size and snow pack water equivalent on visible and near infrared satellite observations of snow. Water Resources Research 17(4): 1213-1221.

Foster, J., G. Liston, R. Koster, R. Essery, H. Behr, L. Dumenil, D. Verseghy, S. Thompson, D. Pollard, and J. Cohen. 1996. Snow cover and snow mass intercomparison of general circulation models and remotely sensed data sets. Journal of Climate 9: 409-426.

Frei, A., and D.A. Robinson. 1998. Evaluation of snow extent and its variability in atmospheric model intercomparison project. Journal of Geophysical Research 103: 8859-8871.

Gupta, R.P., U.K. Haritashya, and P. Singh. 2005. Mapping dry/wet snow cover in the Indian Himalayas using IRS multispectral imagery. Remote Sensing of Environment 97: 458-469.

Hall, D.K., G.A. Riggs, and V.V. Salomonson. 1995. Development of methods for mapping global snow cover using moderate resolution imaging spectroradiometer data. Remote Sensing of Environment 54: 127-140.

Hall, D.K., J.L. Foster, D.L. Verbyla, A.G. Klein, and C.S. Benson. 1998. Assessment of snow-cover mapping accuracy in a variety of vegetation-cover densities in central Alaska. Remote Sensing of Environment 66: 129-137.

Hall, D.K., G.A. Riggs, V.V. Salomonson, N. DiGirolamo, and K.J. Bayr. 2002. MODIS snow cover products. Remote Sensing of Environment 83: 181-194.

Hall, D.K., R.E.J. Kelly, J.L. Foster, and A.T.C. Chang. 2005. Hydrological applications of remote sensing: surface states: snow. In Encyclopedia of hydrological sciences, ed. M.G. Anderson, 34-56. Chichester: Wiley.

Kaur, R., D. Saikumar, A.V. Kulkarni, and B.S. Chaudhary. 2009. Variations in snow cover and snowline altitude in Baspa Basin. Current Science 96(9): 1255-1258.

Khosla, D., J.K. Sharma, and V.D. Mishra. 2011. Snow Cover Monitoring Using Different Algorithm on Awifs Sensor Data. International Journal of Advanced Engineering Sciences and Technologies 7(1): 42-47.

Knight, P. 1999. Glaciers. United Kingdom: Stanley Thornes Ltd.

Konig, M., J.G. Winther, and E. Isaksson. 2001. Measuring snow and glacier ice properties from satellite. Reviews of Geophysics 39(1): 1-27.

Kulkarni, A.V. 2007. Effect of global warming on Himalyan cryosphere. Jalvigyan Samiksha 22: 93-108.

Kulkarni, A.V., and B.P. Rathore. 2003. Snow cover monitoring in baspa basin using IRS WiFS data. Mausam 54: 335-340.

Kulkarni, A.V., S.K. Singh, P. Mathur, and V.D. Mishra. 2006. Algorithm to monitor snow cover using AWiFS data of RESOURCESAT-1 for the Himalayan region. International Journal of Remote Sensing 27(12): 2449-2457.

Matson, M. 1991. NOAA satellite snow cover data. Paleogeography and Paleoecology 90: 213-280.

Matson, M., C.F. Roeplewski, and M.S. Varnadore. 1986. An Atlas of Satellite-Derived Northern Hemisphere Snow Cover Frequency, 75. Washington: National Weather Service.

Negi, H.S., Snehmani, and N.K. Thakur. 2008. Operational Snow Cover Monitoring in NW-Himalaya using Terra and Aqua MODIS Imageries, Proceedings International Workshop on Snow, Ice, Glacier and Avalanches, 11-25. India: IIT Mumbai.

Negi, H.S., A.V. Kulkarni, and B.S. Semwal. 2009. Estimation of snow cover distribution in Beas basin, Indian Himalaya using satellite data and ground measurements. Journal of Earth System Science 118: 525-538.

Nolin, A., and S. Liang. 2000. Progress in bidirectional reflectance modeling and applications for surface particulate media: Snow and soils. Remote Sensing Reviews 14: 307-342.

Ramsay, B.H. 1998. The interactive multi-sensor snow and ice mapping system. Hydrological Processes 12: 1537-1546.
Rango A and Martinec J. 1982. Snow accumulation derived from modified depletion curves of snow coverage, Symposium on Hydrological Aspects of Alpine and High Mountain Areas, IAHS Publication, 138: 83-90.

Rango, A., A.E. Walker, and B.E. Goodison. 2000. Role of snow and ice. In Remote sensing in hydrology and water management, ed. G.A. Schultz and E. Engman, 239-270.

Robinson, D.A., K.F. Dewey, and R.R. Heim. 1993. Global snow cover monitoring-an update. Bulletin of the American Meteorological Society 74(9): 1689-1696.

Salomonsona, V.V., and I. Appel. 2004. Estimating fractional snow cover from MODIS using the normalized difference snow index. Remote Sensing of Environment 89: 351-360.

Shafer, B.A., and C.F. Leaf. 1979. Landsat derived snow cover as an input variable for snowmelt runoff forecasting in Central Colorado, Proc. Final Workshop on Operational Applications of Satellite Snow Cover Observations, NASA, $151-169$.

Slater, P.N. 1980. Remote sensing optics and optical systems. Massachusetts: Addison-Wesley Publishing Company Inc.

Stieglitz, M., A. Ducharne, R. Koster, and M. Suarez. 2001. The impact of detailed snow physics on the simulation of snow cover and subsurface thermodynamics at continental scales. Journal of Hydrometeorology 2(3): 228-242.

Townshend, J.R.G., and C.J. Tucker. 1984. Objective assessment of advanced very high resolution radiometer data for land cover mapping. International Journal of Remote Sensing 5: 497-504.

Tucker, C.J. 1979. Red and photographic infrared linear combinations for monitoring vegetation. Remote Sensing of Environment 8: 127-150.

Tucker, C.J. 1986. Maximum normalized difference vegetation index images for sub-Saharan Africa for 1983-1985. International Journal of Remote Sensing 7: 1383-1384.

Yang, Z.L., R.E. Dickinson, A.N. Hahmann, G.K. Niu, M. Shaikh, X.G. Gao, R.C. Bales, S. Sorooshian, and J.M. Jin. 1999. Simulation of snow mass and extent in general circulation models. Hydrological Processes 13(12-13): 2097-2113.

\section{Submit your manuscript to a SpringerOpen ${ }^{\mathcal{O}}$ journal and benefit from:}

- Convenient online submission

- Rigorous peer review

- Immediate publication on acceptance

- Open access: articles freely available online

- High visibility within the field

- Retaining the copyright to your article

Submit your next manuscript at springeropen.com 